\title{
The Drawbacks and Superiorities of Using IR-Microwave System in Cake and Bread Baking: A Review
}

\author{
K.A. Abbas (Corresponding author) \\ Department of Food Technology, Faculty of Food Science and Technology \\ Universiti Putra Malaysia, 43400 Serdang, Selangor, Malaysia \\ Tel: 60-3-8946-8534 E-mail: ali_kassim@hotmail.com \\ S. M. Abdulkarim \\ Department of Food Science, Faculty of Food Science and Technology \\ Universiti Putra Malaysia, 43400 Serdang, Selangor, Malaysia \\ M. Ebrahimian \\ Department of Food Technology, Faculty of Food Science and Technology \\ Universiti Putra Malaysia, 43400 Serdang, Selangor, Malaysia \\ N. Suleiman \\ Department of Food Technology, Faculty of Food Science and Technology \\ Universiti Putra Malaysia, 43400 Serdang, Selangor, Malaysia
}

\begin{abstract}
This review work tried to highlight and summarize the drawbacks and superiorities of three different heating methods commonly used for baking bread and cakes. These methods are infrared heating, microwave heating and infrared-microwave heating. The literature revealed that infrared heating method usually result in good quality food products, but the system performance is still underdeveloped to meet challenges of the current era. Whereas microwave heating method possesses superior system performance features but present many problems with the eating quality of the final food product. In order to improve both system performance and the food quality, researchers found that the infrared-microwave system is the best alternative. This system (halogen lamp-microwave) is a combination of the first two heating methods and at optimized conditions; the system can produce good quality food with better performance. Studies revealed that the good crust color formation and time saving are the superiorities, but the lower moisture content and lower specific volume are the drawbacks on using such system. The products were firmer as a result of the high moisture loss. Halogen lamp power, microwave power and baking time are found to be the major factors that affect the characteristics of the baked products. Based on the heating effects, it is possible to conclude that microwave heating is the dominant heating mechanism in halogen lamp-microwave combination system. However, this system was still be able to produce acceptable quality of baked products therefore researchers recommended IR-microwave for cake and bread baking.
\end{abstract}

Keywords: Bread, Cake, Baking, Infrared, Microwave, Infrared-Microwave

\section{Introduction}

Although the infrared heating is producing good eating quality baked foods, but many drawbacks are inherent regarding system performance. Therefore the microwave heating was emerging to overcome these drawbacks. However, many quality problems have come into sight again to be associated with microwave-baked products. Microwave-baked products are firm, tough in texture, rapidly staled, dry, lack of color and crust (Sevimli et al., 2005). Cakes baked in a microwave oven had the lowest quality (Sumnu et al., 2005 ${ }^{\mathrm{b}}$ ). It was also found that insufficient starch gelatinization in microwave-baked cakes in which the degree of gelatinization ranged from 55\% to $78 \%$ depending on formulation (Sakiyan et al., 2009).

Microwave heating is also not commonly used in mass production. Among the drawbacks are non-uniformity of heating since it is very much depending on the geometry, thickness and the dielectric properties of the material; there is no common method to monitor or control the electromagnetic field distribution and its effect after the 
microwave is switched on and high in cost (Vadivambal and Jayas, 2007). In order to reduce non-uniformity heating, carousel has been used and Geedipalli et al. (2007) has successfully determined the power absorbed in the food as a function of the angle of rotation of the turntable covering the entire cycle. On using various measures of heating uniformity, it was shown that the carousel helps in increasing the temperature uniformity of the food by about $40 \%$ (Geedipalli et al., 2007).

Besides these drawbacks, Megahey et al. (2005) reported that when used singly in cake baking, the microwave oven at $250 \mathrm{~W}$ showed improved textural properties (springiness, moisture content, firmness) as compared to cake baked in the convective oven. However, in the recent development in baking, microwave heating has been combined with infrared (halogen-lamp) heating (Sevimli et al., 2005). Combination of these two heating methods at optimized conditions resulted in better performance and quality of baked products. Fig. 1 shows the illustration of an IR-microwave combination oven.

Halogen lamp produces near-IR radiation and the electromagnetic spectrum is near visible light with higher frequency and lower penetration. IR radiation affects only the surface of the food and heat transfer through the food takes place by conduction or convection. Therefore, the radiation can cause its temperature to reach the required values for browning. On the other hand, microwave heating happens evenly throughout the food and when IR radiation is added to microwave heating, the heat transfer processes can be modified significantly (Sevimli et al., 2005).

Many studies have focused on the effects of different baking methods on the physical properties of breads and cakes. For example, Keskin et al. (2004) compared the quality of breads baked by different methods; conventional, microwave, halogen lamp and halogen lamp-microwave combination baking methods. Sumnu et al. (2007) studied the same thing, but using different methods which were microwave plus infrared (MIR), microwave plus jet impingement (MJET) and jet impingement (JET). Different methods were also used in a study conducted by Ozkoc et al. $\left(2009^{b}\right)$, which involved microwave, infrared-microwave combination and conventional baking methods, but their focus was on physicochemical properties of breads during storage.

Although IR-microwave system is preferably used in (cake and bread) baking and effective drying, but there is big lack of information about this systems in the literature. As most of the publications talk about comparison of properties of different systems but there is no review paper on the advantages and disadvantages of the IR-microwave system. Moreover there is no real picture summarizing current status of the development in this regards. In the light of above the following subsections have been prepared.

\section{Advantages}

The infrared-microwave combination oven was able to produce brown and crispy products which mainly due to the infrared (halogen lamp) heating. It was possible to obtain cakes with quality comparable to cakes baked in a conventional oven by using the halogen lamp-microwave combination oven.

\subsection{Crust color formation}

According to Sevimli et al. (2005), cakes baked in a halogen lamp-microwave combination oven had specific volume and color values comparable with cakes which were baked using commercial electrical oven. Results of the experiments are as shown in Table 1 (Sevimli et al., 2005). They found that the upper halogen lamp power and the baking time significantly affected the color of the cakes. Sumnu et al. $2005^{\mathrm{b}}$, also confirmed that it was possible to achieve surface color formation in cakes by IR and IR-microwave combination baking.

In the study done by Keskin et al. (2004) it was found that all bread samples baked in microwave oven had similar colors with the dough, therefore their total color change $(\Delta \mathrm{E})$ values were very close to zero. The $\Delta \mathrm{E}$ value of breads baked in IR-microwave oven increased with baking time and halogen lamp oven power (Fig. 2).

The crust color formation is affected by increase in surface temperature of the breads due to increment in halogen power. The required values for surface browning can be achieved by halogen lamp heating which is known to provide low penetration depth and concentrate radiation at the surface. Therefore, similar $\Delta \mathrm{E}$ values with the conventionally baked breads could be achieved with halogen lamp-microwave combination heating (Keskin et al., 2004). It is also supported by Demirekler et al. (2004). The upper halogen lamp power and time were found to be significant in affecting the color change (Demirekler et al., 2004).

In halogen lamp-microwave combination baking, breads baked at $70 \%$ halogen lamp power and $30 \%$ microwave power for $3 \mathrm{~min}$ had $\Delta \mathrm{E}$ value and specific volume similar to conventionally baked breads. Darker colors could be observed when the baking time was extended, while specific volume of the bread decreased and firmness increased in an unacceptably great extends (Keskin et al., 2004). These disadvantages are going to be discussed further in the next section; disadvantages of halogen lamp-microwave baking system. 
When comparing the effect of using different IR powers Sumnu et al. $\left(2005^{\mathrm{b}}\right)$ suggested the best conditions for baking of cakes in IR-microwave combination oven is at $70 \%$ halogen lamp and at $50 \%$ microwave power levels for was 5 minutes. Fig. 3 shows the effect of different IR powers to the colour. Increase in colour was faster using $70 \%$ IR power.

Tireki et al. (2006) also supported that $\Delta \mathrm{E}$ values were lower in microwave drying and higher in infrared drying in their study on bread crumbs production. Infrared-assisted microwave dried crumbs generally had similar color values with the conventionally dried ones (Tireki et al., 2006). However, they did not observed the effect of power on color change as shown in Fig.4.

Demirekler et al. (2004) had reported that increasing the upper halogen lamp power and the baking time will increase the $\Delta \mathrm{E}$ value significantly. However, at higher upper halogen lamp powers, the increase in time was insignificant for the color change of the breads. Similarly, the increase in the microwave power did not affect the color change for short baking times. However, when the baking time was long, the increase in the microwave power increased the color change (Demirekler et al., 2004).

Besides good crust color formation, IR-microwave system is time and energy saving as microwave heating produces even heating throughout the food (Sevimli et al., 2005).

\subsection{Time saving}

The near infrared-microwave combination heating combines the colour and crust formation advantages of near infrared heating with the time saving advantage of microwave heating. When an IR-microwave combination oven was used at this condition conventional baking time of cakes was reduced by about $75 \%$ (Sumnu et al., $2005^{\mathrm{b}}$ ). The increase in microwave oven power level decreased the drying time. In another study but on drying of carrot slices, Sumnu et al. $\left(2005^{\mathrm{a}}\right)$ concluded that the drying time can be reduced up to $98 \%$ when microwave drying was done at the highest power (using halogen lamp-microwave combination system), in comparison to conventional hot-air drying.

Tireki et al. (2006) studied the IR-microwave system in bread crumbs production. The moisture content of the bread crumbs dough was reduced from 40.9 to $8 \%$ in order to have a good quality product. Their findings were summarized in Table 2. Higher reduction in drying time was observed in microwave (96.5-98.6\% reduction) and infrared-assisted microwave (96.8-98.6\% reduction) ovens as compared to conventional baking. Infrared system alone results in $80.2-94.0 \%$ reduction in drying time. Demirekler et al. (2004) also agreed that baking time was significantly reduced using IR-microwave system compared to conventional system.

Microwave drying at the highest power and halogen lamp-microwave combination drying reduced the drying time significantly. It was suggested that halogen lamp-microwave combination oven can be used when the product moisture content is required to be reduced to very low values (Tireki et al., 2006).

\section{Disadvantages}

IR-microwave combination system had reduced some of the weaknesses of single microwave heating system to a certain extend to render the product more acceptable. However, many published papers which covered the effect of the IR-microwave system had concluded that the system had resulted in less desirable baked products in term of its specific volume, moisture content and texture.

\subsection{Lower specific volume}

Table 3 revealed that bread samples baked in halogen lamp-microwave combination oven had the highest specific volume. However, Keskin et al. (2004) concluded that microwave baked breads had higher specific volume as compared to others. This is because, specific volume of breads baked in halogen lamp-microwave combination oven decreased as baking time increased (Fig. 5). The specific volume of breads also decreased with the increment of halogen lamp power. The crumb expansion is retarded because of immediate thick crust formation at the breads' surface. The crust was formed due to focused radiation provided by halogen lamp heating on the breads' surface.

In comparison, a study by Sumnu et al. (2007) showed that breads baked in MIR system had lowest final volume due to highest loss in moisture content, followed by samples baked in MJET and JET systems. The final volume of breads baked in MIR oven is $9.1 \%$ lower than that of baked in MJET. This is due to the faster heating of the MIR. In addition, MIR has low surface temperature such that the rigid outer crust of the breads does not develop that would allow the gas generated in the dough to expand the volume (instead the gas is released). This also explains the lower height of breads (Fig. 6) baked in MIR than breads baked in other heating modes. 
Whereas, in a study on bread baked in IR-microwave oven, Demirekler et al., 2004 reported that when time and the microwave power increased, a higher specific volume was observed. However, the increase in the upper halogen lamp power resulted in a decrease in the specific volume of the breads. However, the power of the lower halogen lamp did not affect any of the quality parameters significantly (Demirekler et al., 2004).

\subsection{Lower moisture content due to high weight loss}

In the study done by Keskin et al. (2004), for all oven types, weight loss of breads was affected by baking time and oven power proportionally, but not significantly affected by the temperature increment (Figs. 7-9). However, in halogen lamp-microwave combination oven, increment in the microwave and halogen lamp power caused higher weight loss of the bread samples (17.86\%) as shown in Fig. 9.

Higher rate of weight loss was observed in breads baked in microwave oven at $100 \%$ power compared to $50 \%$ power because during the same baking time, more microwaves were coupled to the bread samples as power was increased which resulted in more heating (Fig. 8). Whereas increase in halogen power caused the bread samples to be subjected to more radiation, thus weight loss increased, indicating moisture loss.

In halogen lamp-microwave combination baking, the microwave power was more effective on weight loss than halogen lamp power. It can be seen in Fig. 9, which shows that breads baked with 50\% microwave and $60 \%$ halogen lamp power undergoes the highest weight loss.

Similarly, Sumnu et al. (2007) also found that MIR heating leads to higher moisture loss. But in this study, MIR was compared with MJET and JET baking methods. In each method, the loss was observed at the end of baking, where highest moisture loss was observed in bread samples that undergo MIR baking method, followed by MJET and JET methods. This is shown in Fig. 10.

However, according to Ozkoc et al. (2009), when both infrared-microwave combination and conventional baking methods were compared, microwave-baked breads found to have lowest moisture content (Table 5).

In an IR-microwave system, as the baking time, the upper halogen lamp power, and the microwave and halogen lamp powers increased, the weight loss of the breads increased. These findings were strongly supported by Demirekler et al. (2004) and Sevimli et al. (2005). When the microwave power and the upper halogen lamp power were compared, the microwave power was found to be more effective and significant in resulting in weight loss (Demirekler et al., 2004, Sevimli et al., 2005).

On the other hand, on a study on bread crumbs dough, Tireki et al., 2006, reported that all IR-microwave drying methods were found to be effective in increasing water binding capacity as shown in Fig. 11, compared to conventional baking. At fixed microwave powers increase of halogen lamp power did not affect the water binding capacity in infrared-assisted microwave drying (Tireki et al., 2006).

In another study by Datta and Ni (2002), heating by microwave-only was found to result in moisture build-up due to enhanced (pressure-driven) flow of moisture to the surface and cold ambient air is unable to remove moisture at a high-rate. When microwave and infrared heating (using hot-air) was combined, it was discovered that surface moisture was reduced and the reduction it is very much depending on the power level. The phenomenon is illustrated in Fig. 12. Infrared was more effective in reducing surface moisture and increasing surface temperature, compared to hot air. This is perhaps due to much lower surface heat flux for hot air compared to the infrared energy (Datta and Ni, 2002).

From the composition point of view, Keskin et al., 2007, concluded that the dielectric properties and quality parameters (including moisture content) of breads baked in infrared-microwave combination oven were dependent on gum type. It is depends on the water binding capacity of the gums to retain moisture in the baked products. They concluded that $\kappa$-carrageenan resulted in undesirable final bread quality as the dielectric constant and its loss factor were found to be the highest among the other gums. Thus, it results in very dry, firm and highest weight loss product. On the other hand, xanthan-guar blend addition improved bread quality. The breads formulated with xanthan-guar blend has high specific volume and porosity and low hardness values. The findings by Keskin et al., 2007, were summarized in Table 6 and Fig. 13.

Sakiyan et al. (2007) also confirmed that dielectric constant and loss factor of cakes are dependent on formulation, baking time, and temperature. The increase in baking time decreased dielectric constant and loss factor of cakes. These parameters were measured by the porosity and moisture content of the cakes. The increase in the fat content of the cake formulations increased its dielectric properties.

However, the ability of IR-microwave heating system to reduce the moisture content the lowest possible was claimed to be good and might be applicable in the instant soups and snack foods industry. This is due to the 
higher rehydration potential of microwave dried/baked products (especially starchy products) as reported by Khraisheh et al. (2004). Sumnu et al. $\left(2005^{\mathrm{a}}\right)$ found that carrot slices dried in microwave and halogen lamp-microwave combination oven also had significantly higher rehydration ratio and less colour deterioration. In addition, they also recommended halogen lamp-microwave combination oven in the production of food where its moisture content is required to be reduced to very low values (Sumnu et al., 2005 ${ }^{\mathrm{a}}$ ).

\subsection{Firmer product}

The texture and density of baked products such as bread and cakes are controlled by the way their rheology and vapor content change during the baking process (Mondal and Datta, 2008). Microwave baked products are high in weight loss, thus, having higher firmness values i.e. the cakes and breads are quite dry and hard (refer Table 1 for cakes and Table 8 for breads). This is happened due to rapid heating by microwave which enhances the evaporation process. It was possible to reduce the firmness of cakes baked in a halogen lamp-microwave combination oven by providing the required humidity within the oven during baking (Sevimli et al., 2005).

Table 7 shows that bread samples baked in halogen lamp-microwave combination baking system had the highest firmness $(3.05 \mathrm{~N})$ compared to breads baked with other methods.

During baking at $100 \%$ power, firmness of breads increased sharply which can be related to high rate of moisture loss. The firmness was not significantly affected by the increase in halogen power. However, the crumb firmness was extremely increased in microwave power from $30 \%$ to $50 \%$. This evidence showed that firmness of breads is more affected by microwave heating in halogen lamp-microwave combination oven (Fig. 14), similarly to the study done by Keskin et al. (2004), where the same factor is more dominant in affecting weight loss of the breads. At the final stages of baking, the breads undergo extreme drying which caused sudden increase in their firmness.

During halogen lamp baking, crumb firmness of breads was found to be decreased while in conventional and halogen lamp oven, firmness of breads baked was found to be negatively correlated to their specific volumes. But on using halogen lamp-microwave combination baking, the firmness of breads baked was not found to be correlated to their specific volume (Keskin et al., 2004).

According to Demirekler et al., 2004, baking time and microwave power were the most significant factors in increasing the firmness in an IR-microwave oven. They said at shorter baking times and lower microwave power combinations, firmness values similar to those of conventionally baked breads were observed. The increase in the firmness of the breads with respect to time may be explained by the increase in weight loss during the baking process. For constant baking time and power of the lower halogen lamp, the optimum firmness value was observed at lower microwave and upper halogen lamp powers (Demirekler et al., 2004)

Keskin et al. (2005) applied IR-microwave heating (halogen lamp-microwave system) on cookies. They also confirmed that the hardness values of the cookies increased with increasing baking time and/or halogen power. In addition, the microwave power also contributed to cookie hardness. The best cookies baking condition in a halogen lamp-microwave combination oven was suggested at $70 \%$ halogen lamp and $20 \%$ microwave power levels for $5.5 \mathrm{~min}$. The baking time of these cookies is half of that required in conventional baking (Keskin et al., 2005). Fig. 15 showed the gelatinization properties of cookies (which was assessed using Rapid Visco Analyser) baked in different ovens.

Keskin et al. (2007) also confirmed crumb firmness of breads baked in infrared-microwave combination oven was found to be higher as compared to that of conventionally baked ones. However, they had suggested that the addition of different gums into the bread formulation would be able to prevent this problem. Different gums will have different water binding capacity. Hence, it will affect the viscosity of the solution. Thus, it influences the dielectric properties and microwave heatability of these food. Table 9 shows the water binding capacity of dough as affected by the type of gums used in the formulations. Their findings were explained earlier in the moisture content topic (page 17).

In contrary, Sumnu et al. $\left(2005^{\mathrm{b}}\right)$ found that IR-microwave combination baking reduced weight loss in cakes, as showed in Fig. 16. Similar pattern was also observed in the firmness of the baked cakes (Sumnu et al., 2005 ).

Other relevant papers on IR-microwave system mainly focused on the starch gelatinization during baking, development of pores and the usage of NIR in the analysis and prediction of the milling and baking parameters of wheat.

Sakiyan et al. (2009) studied the effects of different baking ovens and different cake formulations on the degree of starch gelatinization during cake baking. Starch gelatinization levels were examined using Differential Scanning Calorimeter (DSC) and Rapid Visco Analyzer (RVA). Both DSC and RVA results showed that 
increasing baking time increased gelatinization level for all baking types as shown in Table 10 and 11 (Sakiyan et al., 2009). Generally, microwave heating resulted in high final viscosity due to high moisture lost in short time. Meanwhile, conventional baking took the longest baking time. IR-microwave combination oven gave the properties in between these two.

They also found that addition of fat reduced the degree of starch gelatinization in conventional baking. However, fat enhanced the gelatinization in microwave and IR-microwave combination ovens. There was insufficient starch gelatinization in microwave-baked cakes in which the degree of gelatinization ranged from $55 \%$ to $78 \%$ depending on formulation. On the other hand, it ranged from $85 \%$ to $93 \%$ in conventionally baked cakes. Combining infrared with microwaves increased degree of starch gelatinization (70-90\%) (Sakiyan et al., 2009).

Palav and Seetharaman (2007) did a study on the impact of microwave heating on the physico-chemical properties of a starch-water model system. They concluded that microwave heating alone leads to different mechanism of starch gelatinization compared to conduction heating. The vibrational motion and the rapid increase in temperature also result in granule rupture and formation of film polymers coating the granule surface (Palav and Seetharaman, 2007).

Ozkoc et al. $\left(2009^{\mathrm{a}}\right)$ analyzed the pores size (using Scanning Electron Microscope) of breads baked in different ovens. Pores of breads baked in conventional oven were found to be smaller, and had spherical, oval-like shape as compared to the ones baked in IR-microwave combination oven. Their cell structure was also more homogeneous. Meanwhile, IR-microwave combination oven resulted in pores that were so close to each other which subsequently lead to coalescence of the gas cells to form channels, thus, the pores were no longer spherical. The starch granules in conventionally baked breads were more distorted and seen as a continuous sheet of gelatinized starch. On the other hand, granular residues and continuous starch structure was observed together in IR-microwave combination heating (Ozkoc et al., 2009 ${ }^{\mathrm{a}}$ ).

Jirsa et al. (2008) found that near infrared reflectance spectroscopy (NIRS) has accurately analyzed and predicted the milling and baking parameters of wheat. The parameters measured are flour extraction, protein content, Zeleny sedimentation, deformation energy, gas volume and baking volume of wheat from many varieties. The range of spectra used was from 400 to $2500 \mathrm{~nm}$. They also suggested NIRS to be used in the determination and screening performance of wheat for its rheological traits (deformation energy, gas volume and specific loaf volume).

\section{Conclusion}

The IR-microwave system is a new emerging system suggested for baking. Microwave heating was found to be the dominant heating mechanism in halogen lamp-microwave combination baking in terms of affecting weight loss and texture development. The advantages of using IR-microwave system enhance the crust and color formation with energy saving process. The IR-microwave system were noted for lower specific volume and moisture content of the baked products, even the products are also firm and hard due to high weight/moisture loss.

It is not advisable to bake breads by using only halogen lamp mode of the oven because of the formation of the very thick bread crust. Halogen lamp-microwave combination baking provided color similar to the conventionally baked products but the weight loss and firmness of breads were still higher as compared to conventionally baked products. Nevertheless, many researchers recommended IR-microwave for cake and bread baking.

\section{References}

Datta, A.K. and Ni, H. (March 2002). Infrared and hot-air-assisted microwave heating of foods for control of surface moisture. Journal of Food Engineering 51(4):355-364.

Demirekler, P., Sumnu, G. and Sahin, S. (2004). Optimization of bread baking in a halogen lamp-microwave combination oven by response surface methodology. European Food Research Technology 219:341-347. DOI 10.1007/s00217-004-0969-3.

Geedipalli, S.S.R., Rakesh, V. and Datta, A.K. (2007). Modeling the heating uniformity contributed by a rotating turntable in microwave ovens. Journal of Food Engineering 82:359-368.

Jirsa, O., Hrušková, M. and Švec, I. (2008). Near-infrared prediction of milling and baking parameters of wheat varieties. Journal of Food Engineering 87: 21-25.

Keskin, S.O., Sumnu, G. and Sahin, S. (2004). Bread baking in halogen lamp-microwave combination oven. Food Research International 37:489-495. 
Keskin, S.O., Oztiirk, S., Sahin, S., Koksel, H. and Sumnu, G. (2005). Halogen lamp-microwave combination baking of cookies. European Food Research Technology 220:546-551. DOI 10.1007/s00217-005-1131-6.

Keskin, S.O., Sumnu, G. and Sahin, S. (2007). A study on the effects of different gums on dielectric properties and quality of breads baked in infrared-microwave combination oven. European Food Research Technology 224:329-334. DOI 10.1007/s00217-006-0334-9.

Khraisheh, M.A.M., McMinn, W.A.M. and Magee, T.R.A. (2004). Quality and structural changes in starchy foods during microwave and convective drying. Food Research International 37:497-503.

Megahey, E.K., McMinn, W.A.M. and Magee, T. R. A. (2005). Experimental study of microwave baking of Madeira cake batter. Food and Bioproducts Processing 83(C4): 277-287.

Mondal, A. and Datta, A.K. (2008). Bread baking - A review. Journal of Food Engineering 86:465-474.

Ozkoc, S.O., Sumnu, G. and Sahin, S. $\left(2009^{\mathrm{a}}\right)$. The effects of gums on macro and micro-structure of breads baked in different ovens. Food Hydrocolloids 23:2182-2189.

Ozkoc, S.O., Sumnu, G., Sahin, S., and Turabi, E. $\left(2009^{\mathrm{b}}\right)$. Investigation of physicochemical properties of breads baked in microwave and infrared-microwave combination ovens during storage. European Food Research Technology 228:883-893.

Palav, T. and Seetharaman, K. (2007). Impact of microwave heating on the physico-chemical properties of a starch-water model system. Carbohydrate Polymers 67:596-604.

Sakiyan, O., Sumnu, G. Sahin, S. and Meda, V. (2007). Investigation of dielectric properties of different cake formulations during microwave and infrared-microwave combination baking. Journal of Food Science 72(4):E205-E213.

Sakiyan, O., Sumnu, G., Sahin, S., Meda, V., Koksel, H. and Chang, P. (May 2009). A study on degree of starch gelatinization in cakes baked in three different ovens. Food Bioprocess Technology DOI 10.1007/s11947-009-0210-2.

Sevimli, K.M., Sumnu, G. and Sahin, S. (2005). Optimization of halogen lamp-microwave combination baking of cakes: a response surface methodology study. European Food Research Technology 221:61-68.

Sumnu, G., Turabi, E. and Oztop, M. (2005 $)$. Drying of carrots in microwave and halogen lamp-microwave combination ovens. LWT 38:549-553.

Sumnu, G., Sahin, S., and Sevimli, M. $\left(2005^{\mathrm{b}}\right)$. Microwave, infrared and infrared-microwave combination baking of cakes. Journal of Food Engineering 71:150-155.

Sumnu, G., Datta, A.K., Sahin, S., Keskin, S.O., and Rakesh, V. (2007). Transport and related properties of breads baked using various heating modes. Journal of Food Engineering 78:1382-1387.

Tireki, S., Sumnu, G. and Esin, A. (2006). Production of bread crumbs by infrared-assisted microwave drying. European Food Research Technolology 222:8-14. DOI 10.1007/s00217-005-0109-8.

Vadivambal, R. and Jayas, D.S. (2007). Changes in quality of microwave-treated agricultural products - a review. Biosystems Engineering 98:1 - 16.

Table 1. Response values for cakes baked in the halogen lamp-microwave combination oven and control cakes (ref: K. Melike Sevimli et al., 2005b)

\begin{tabular}{lcc}
\hline Response & $\begin{array}{l}\text { Halogen lamp- } \\
\text { microwave combi- } \\
\text { nation baked cakes }\end{array}$ & $\begin{array}{l}\text { Control cakes } \\
\text { (conventionally } \\
\text { baked for 24 min) }\end{array}$ \\
\hline Weight loss $(\%)$ & 7.500 & 10.290 \\
Specific volume $(\mathrm{ml} / \mathrm{g})$ & 1.660 & 1.650 \\
Firmness $(\mathrm{N})$ & 0.330 & 0.440 \\
Color $(\Delta E)$ & 54.00 & 67.820 \\
Springiness $(\mathrm{mm})$ & 2.756 & 2.793 \\
Gumminess $(\mathrm{kgf})$ & 0.017 & 0.019 \\
Adhesiveness $(\mathrm{kgf} \mathrm{mm})$ & 0.002 & 0.001 \\
\hline
\end{tabular}


Table 2. Drying times for different drying treatments (ref: Tireki et al., 2006)

\begin{tabular}{ll}
\hline Drying method & Drying time (s) \\
\hline Conventional & 7560 \\
$30 \%$ microwave power only & 265 \\
$50 \%$ microwave power only & 148 \\
$70 \%$ microwave power only & 106 \\
$30 \%$ halogen power only & 1500 \\
$50 \%$ halogen power only & 780 \\
$70 \%$ halogen power only & 450 \\
$30 \%$ microwave power and 30\% halogen power & 240 \\
$30 \%$ microwave power and 50\% halogen power & 202 \\
$30 \%$ microwave power and 70\% halogen power & 195 \\
$50 \%$ microwave power and 30\% halogen power & 142 \\
$50 \%$ microwave power and 50\% halogen power & 139 \\
$50 \%$ microwave power and 70\% halogen power & 135 \\
$70 \%$ microwave power and 30\% halogen power & 111 \\
$70 \%$ microwave power and 50\% halogen power & 105 \\
$70 \%$ microwave power and 70\% halogen power & 103 \\
\hline
\end{tabular}

Table 3. Effects of different baking methods on weight loss (\%) of breads (ref: Keskin et al., 2004)

\begin{tabular}{|c|c|}
\hline Baking methods & $\begin{array}{c}\text { Specific volume } \\
(\mathrm{ml} / \mathrm{g})\end{array}$ \\
\hline Conventional & 1.60 \\
\hline Microwave & 2.04 \\
\hline Halogen lamp & 1.44 \\
\hline Halogen lamp-microwave combination & 2.57 \\
\hline
\end{tabular}

Table 4. Effects of different baking methods on weight loss (\%) of breads (ref: Keskin et al., 2004)

\begin{tabular}{|c|c|}
\hline Baking methods & Weight loss (\%) \\
\hline Conventional & 4.06 \\
\hline Microwave & 10.80 \\
\hline Halogen lamp & 8.20 \\
\hline Halogen lamp-microwave combination & 17.86 \\
\hline
\end{tabular}

Table 5. Moisture content of control breads baked in different ovens during staling at 0 hour (ref: Ozkoc et al., 2009)

\begin{tabular}{|c|c|}
\hline Oven type & Moisture content (\%) \\
\hline Microwave-control & $35.2 \pm 0.12$ \\
\hline Combination-control & $36.0 \pm 0.17$ \\
\hline Conventional-control & $38.2 \pm 0.11$ \\
\hline
\end{tabular}


Table 6. Moisture content data for breads formulated with different gums baked in infrared-microwave combination oven (ref: Keskin et al., 2007)

\begin{tabular}{ll}
\hline Bread type & $\begin{array}{l}\text { Moisture } \\
\text { content }(\%)\end{array}$ \\
\hline Control & $35.98 \mathrm{a} *$ \\
Xanthan & $36.07 \mathrm{a}$ \\
Guar & $35.81 \mathrm{a}$ \\
Xanthan-guar & $36.04 \mathrm{a}$ \\
k-carrageenan & $35.78 \mathrm{a}$ \\
\hline
\end{tabular}

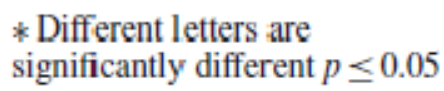

Table 7. Effects of different baking methods on firmness (N) of breads (ref: Keskin et al., 2004)

\begin{tabular}{|c|c|}
\hline Baking methods & Firmness (N) \\
\hline Conventional & 0.67 \\
\hline Microwave & 2.88 \\
\hline Halogen lamp & 0.80 \\
\hline Halogen lamp-microwave combination & 3.05 \\
\hline
\end{tabular}

Table 8. Comparison of responses for conventionally baked breads and responses calculated for the optimum point for halogen lamp-microwave combination oven baked bread (ref: Demirekler et al., 2004).

\begin{tabular}{lcc}
\hline Responses & Conventional baking & $\begin{array}{c}\text { Halogen lamp-mic rowave } \\
\text { combination oven baking }\end{array}$ \\
\hline Weight loss (\%) & 4.06 & 4.39 \\
$\Delta E$ & 35.7 & 34.8 \\
Specific volume (ml/g) & 1.63 & 1.70 \\
Firmness (N) & 0.71 & 0.86 \\
Porosity & 64.1 & 65.3 \\
Chewiness (N mm) & 1.05 & 1.38 \\
Springiness (mm) & 2.92 & 3.00 \\
\hline
\end{tabular}

Table 9. Water binding capacity values for dough samples formulated with different gums (ref: Keskin et al., 2007)

\begin{tabular}{ll}
\hline Dough type & WBC $(\mathrm{w} \backslash \mathrm{w})$ \\
\hline Control & $0.551 \mathrm{~b} *$ \\
Xanthan & $0.910 \mathrm{a}$ \\
Guar & $0.621 \mathrm{~b}$ \\
Xanthan-guar & $0.887 \mathrm{a}$ \\
k-carrageenan & $0.571 \mathrm{~b}$ \\
\hline
\end{tabular}

*Different letters are

significantly different $p \leq 0.05$ 
Table 10. RVA characteristics of non-fat cake samples baked in different ovens (ref: Sakiyan et al., 2009)

\begin{tabular}{lccccccc}
\hline Baking type & $\begin{array}{l}\text { Baking time } \\
\text { (min) }\end{array}$ & $\begin{array}{l}\text { Peak viscosity } \\
\text { (cp) }\end{array}$ & $\begin{array}{l}\text { Trough } \\
\text { (cp) }\end{array}$ & $\begin{array}{l}\text { Break down } \\
\text { (cp) }\end{array}$ & $\begin{array}{l}\text { Final viscosity } \\
\text { (cp) }\end{array}$ & $\begin{array}{l}\text { Setback } \\
\text { Peak time } \\
\text { (s) }\end{array}$ \\
\hline Batter & 22 & 190.00 & 162.00 & 28.00 & 376.00 & 214.00 & 6.20 \\
Conventional & 28 & $92.00 \mathrm{~b}$ & $71.00 \mathrm{~b}$ & $21.00 \mathrm{a}$ & $135.00 \mathrm{~b}$ & $64.00 \mathrm{a}$ & $6.80 \mathrm{a}$ \\
Conventional & 2 & $74.00 \mathrm{~b}$ & $60.00 \mathrm{~b}$ & $14.00 \mathrm{a}$ & $124.00 \mathrm{~b}$ & $64.00 \mathrm{a}$ & $6.87 \mathrm{a}$ \\
Microwave & 2.5 & $176.00 \mathrm{a}$ & $161.00 \mathrm{a}$ & $15.00 \mathrm{a}$ & $233.50 \mathrm{a}$ & $72.50 \mathrm{a}$ & $6.17 \mathrm{a}$ \\
Microwave & 3 & $163.50 \mathrm{a}$ & $130.00 \mathrm{a}$ & $33.50 \mathrm{a}$ & $232.50 \mathrm{a}$ & $102.50 \mathrm{a}$ & $5.97 \mathrm{a}$ \\
Microwave & 3.5 & $127.50 \mathrm{a}$ & $110.50 \mathrm{a}$ & $17.00 \mathrm{a}$ & $199.00 \mathrm{a}$ & $88.50 \mathrm{a}$ & $6.43 \mathrm{a}$ \\
IR-MW Comb & 4.5 & $149.00 \mathrm{ab}$ & $116.00 \mathrm{ab}$ & $33.00 \mathrm{a}$ & $208.00 \mathrm{ab}$ & $85.00 \mathrm{a}$ & $6.40 \mathrm{a}$ \\
IR-MW Comb & 5.5 & $97.33 \mathrm{ab}$ & $99.67 \mathrm{ab}$ & $23.67 \mathrm{a}$ & $171.67 \mathrm{ab}$ & $72.00 \mathrm{a}$ & $6.80 \mathrm{a}$ \\
IR-MW Comb & & $81.00 \mathrm{ab}$ & $16.33 \mathrm{a}$ & $123.00 \mathrm{ab}$ & $42.00 \mathrm{a}$ & $6.93 \mathrm{a}$ \\
\hline
\end{tabular}

Baking types with different letters ( $\mathrm{a}$, b) are significantly different $(p \leq 0.05$ )

$I R-M W$ Comb infrared-microwave combination

Table 11. RVA characteristics of cake samples containing $25 \mathrm{~g}$ fat $/ 100 \mathrm{~g}$ flour baked in different ovens (ref: Sakiyan et al., 2009)

\begin{tabular}{|c|c|c|c|c|c|c|c|}
\hline Baking type & $\begin{array}{l}\text { Baking time } \\
\text { (min) }\end{array}$ & $\begin{array}{l}\text { Peak viscosity } \\
\text { (cp) }\end{array}$ & $\begin{array}{l}\text { Trough } \\
\text { (cp) }\end{array}$ & $\begin{array}{l}\text { Break down } \\
\text { (cp) }\end{array}$ & $\begin{array}{l}\text { Final viscosity } \\
\text { (cp) }\end{array}$ & Set back & $\begin{array}{l}\text { Peak time } \\
\text { (s) }\end{array}$ \\
\hline Batter & & 198.00 & 183.00 & 15.00 & 356.00 & 173.00 & 6.57 \\
\hline Conventional & 22 & $94.00 \mathrm{~b}$ & $78.00 \mathrm{~b}$ & $16.00 \mathrm{a}$ & $124.00 \mathrm{~b}$ & $46.00 \mathrm{a}$ & $6.93 \mathrm{a}$ \\
\hline Conventional & 28 & $80.00 \mathrm{~b}$ & $57.00 \mathrm{~b}$ & $23.00 \mathrm{a}$ & $129.00 \mathrm{~b}$ & $72: 00 \mathrm{a}$ & $6.53 \mathrm{a}$ \\
\hline Microwave & 2 & $175.00 \mathrm{a}$ & $158.00 \mathrm{a}$ & $17.00 \mathrm{a}$ & $264.00 \mathrm{a}$ & $106.00 \mathrm{a}$ & $6.00 \mathrm{~b}$ \\
\hline Microwave & 2.5 & $172.00 \mathrm{a}$ & $127.00 \mathrm{a}$ & $45.00 \mathrm{a}$ & $236.50 \mathrm{a}$ & $109.50 \mathrm{a}$ & $5.93 \mathrm{~b}$ \\
\hline Microwave & 3 & $147.33 \mathrm{a}$ & $11733 \mathrm{a}$ & $30.00 \mathrm{a}$ & $212.00 \mathrm{a}$ & $94.67 \mathrm{a}$ & $6.04 b$ \\
\hline IR-MW Comb & 3.5 & $136.00 \mathrm{~b}$ & $117.00 \mathrm{ab}$ & $19.00 \mathrm{a}$ & $210.00 \mathrm{ab}$ & 93.00 a & $6.60 \mathrm{a}$ \\
\hline IR-MW Comb & 4.5 & $116.00 \mathrm{~b}$ & $81.50 \mathrm{ab}$ & $34.50 \mathrm{a}$ & $143.00 \mathrm{ab}$ & $61.50 \mathrm{a}$ & $6.93 \mathrm{a}$ \\
\hline IR-MW Comb & 5.5 & $96.50 \mathrm{~b}$ & $73.00 \mathrm{ab}$ & $23.50 \mathrm{a}$ & $132.50 \mathrm{ab}$ & $59.50 \mathrm{a}$ & $6.63 \mathrm{a}$ \\
\hline
\end{tabular}

Baking types with different letters (a, b) are significantly different ( $p \leq 0.05)$

$I R-M W$ Comb infrared-microwave combination

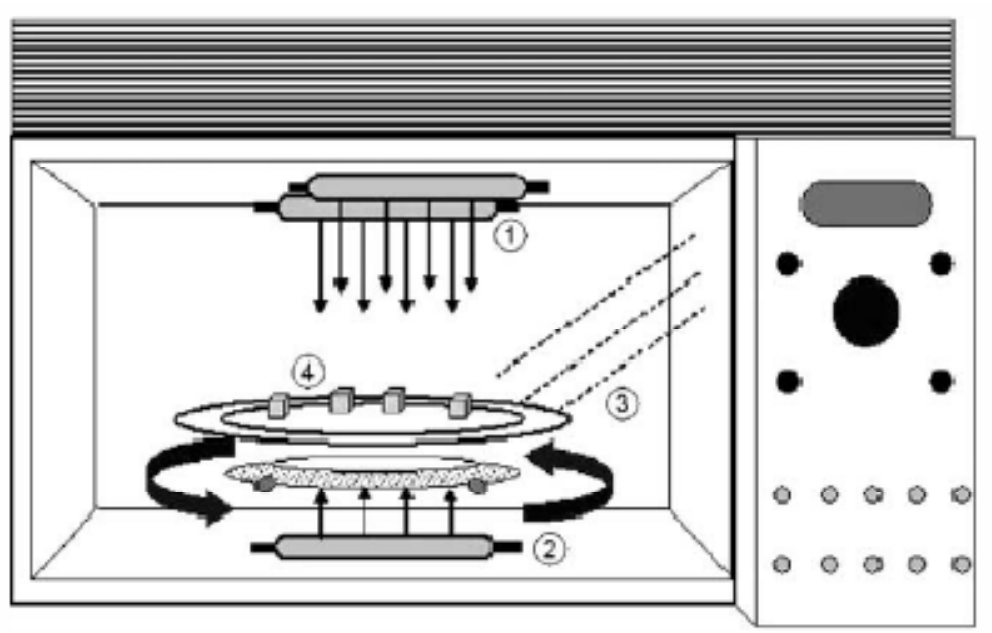

Figure 1. Illustration of IR-microwave combination oven.

(1) Upper halogen lamps, (2) Lower halogen lamp, (3) Microwaves, (4) Turntable (ref: Sumnu et al., 2005 ) 


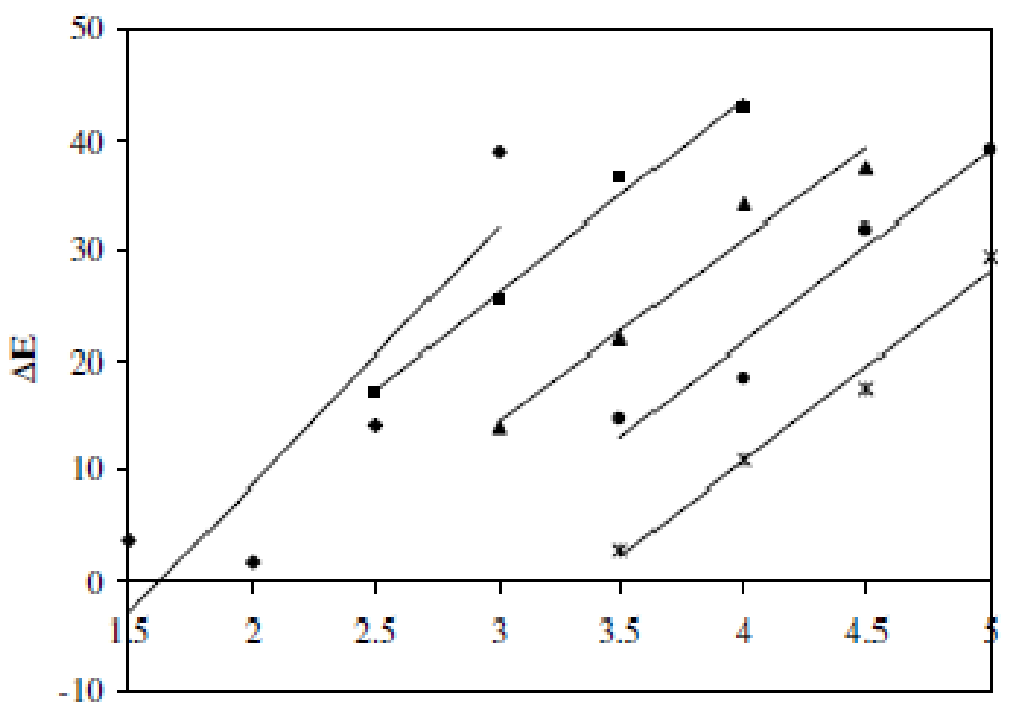

Baking time (min)

Figure 2. Changes of color ( $\Delta \mathrm{E}$ value) of breads during halogen lamp- microwave combination baking at different at different halogen lamp (H) and microwave (MW) powers. ( ) H, 60\% and MW, 50\%; (๘) H, 70\%

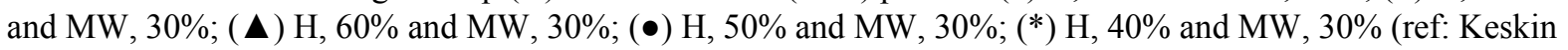
et al., 2004)

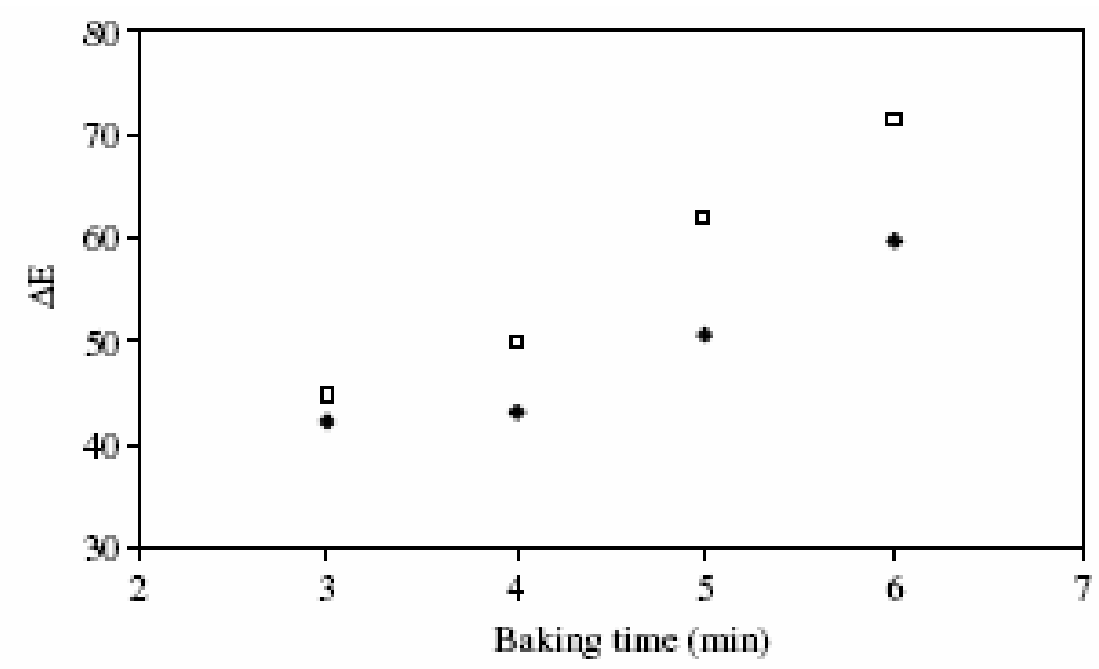

Figure 3. Changes in colour ( $\Delta \mathrm{E}$ value) of cakes during IR-microwave combination baking at $50 \%$ microwave power and at different IR powers. (४): 50\%, (口): 70\% (ref: Sumnu et al., 2005b). 


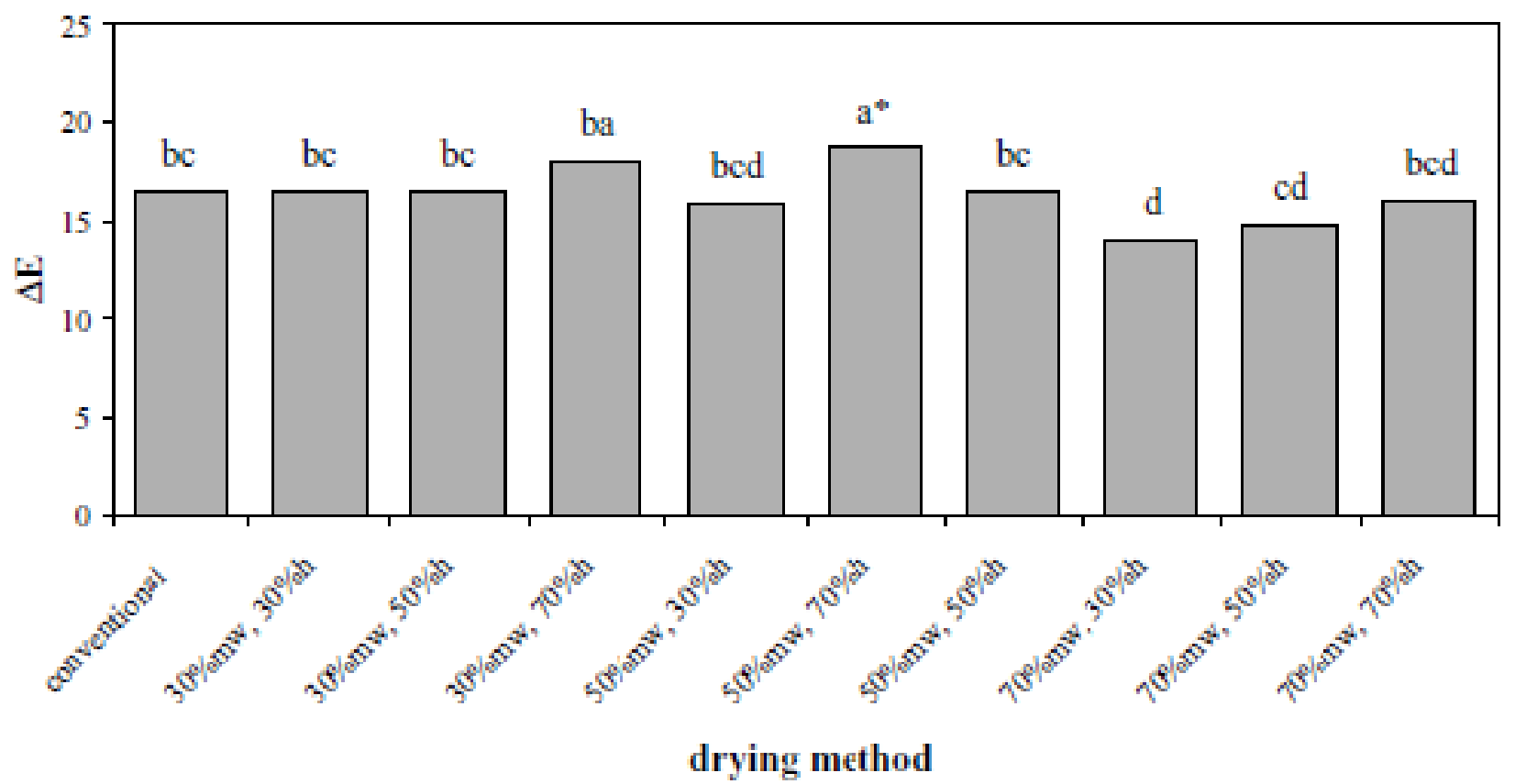

Figure 4. Effect of infrared-assisted microwave drying on $\Delta \mathrm{E}$ values of bread crumbs.

*Means bars containing different letters are significantly different ( $\mathrm{p} \leq 0.05)$ (ref: Tireki et al., 2006)

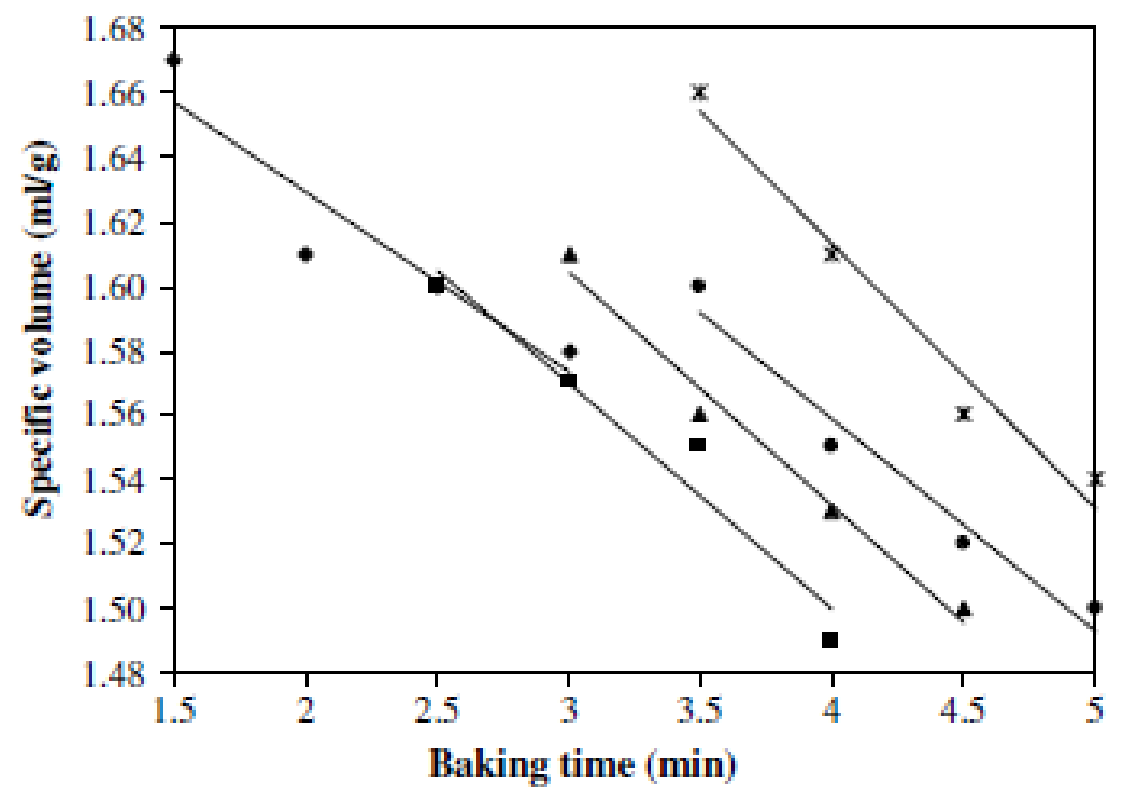

Figure 5. Changes of specific volume of breads during halogen lamp-microwave combination baking at different

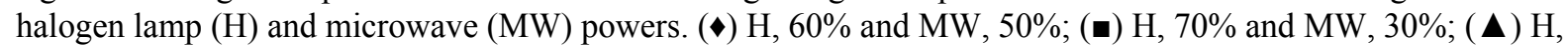
$60 \%$ and MW, 30\%; (•) H, 50\% and MW, 30\%; (*) H, 40\% and MW, 30\% (ref: Ozge Keskin et al., 2004) 


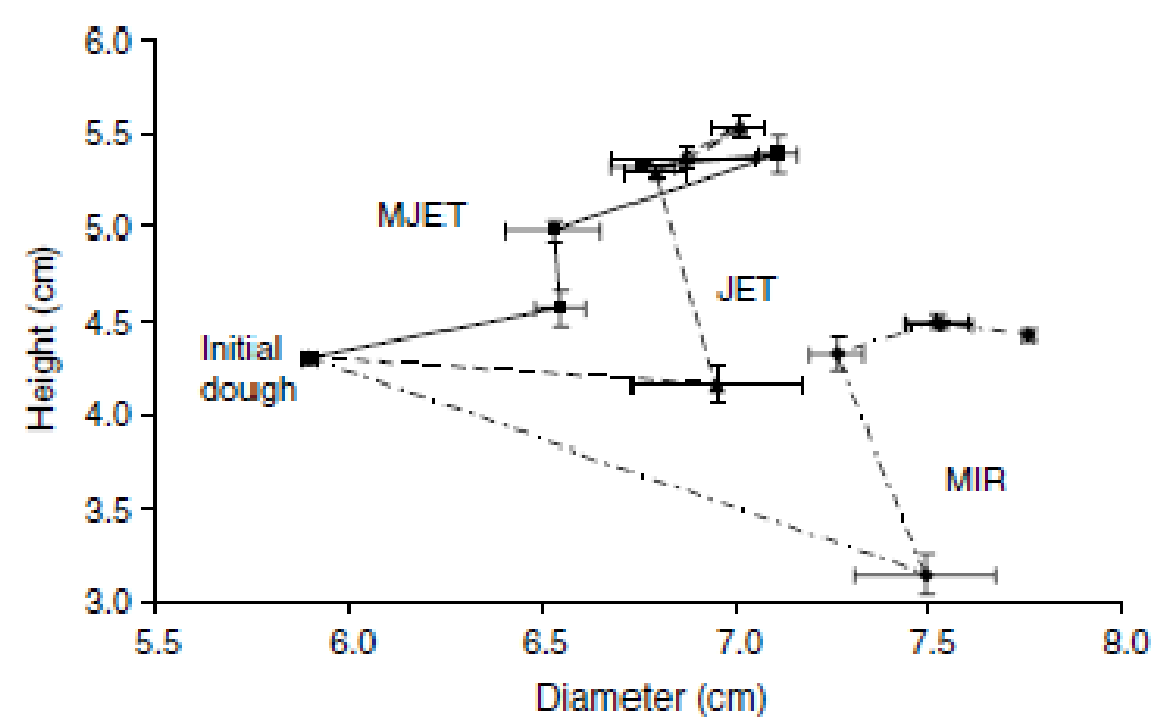

Figure 6. History of dimension changes in bread during baking using different heating modes. The baking times for MJET are 0, 2, 3.5 and $6.5 \mathrm{~min}$, for JET are 0, 2, 3.5, 6 and $8 \mathrm{~min}$, and for MIR are 0, 2, 3, 4, 6 and 8 min, respectively. Error bars represent range of height and diameter in replicates (ref: Sumnu et al., 2007)

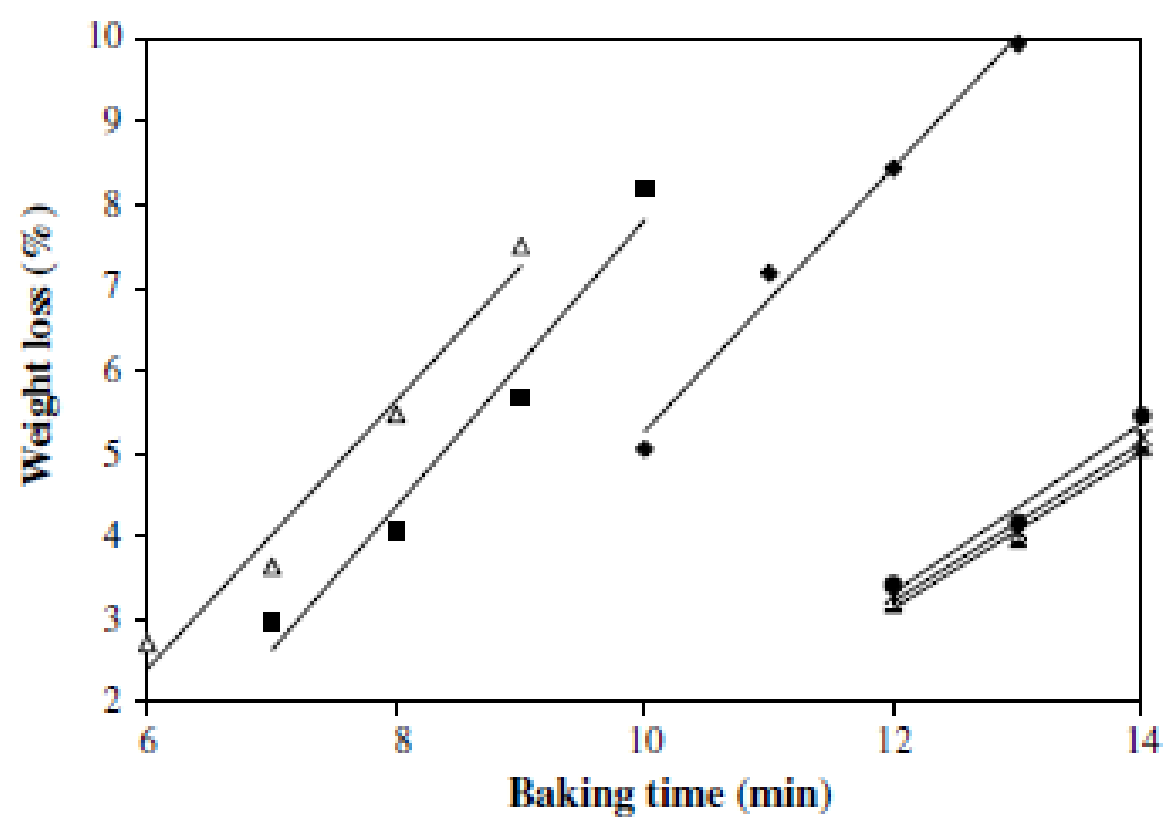

Figure 7. Weight losses of breads during conventional oven and halogen lamp baking at different temperatures

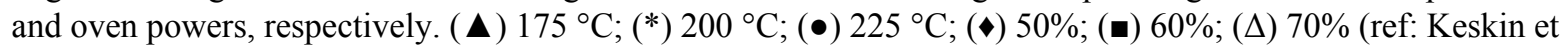
al., 2004) 


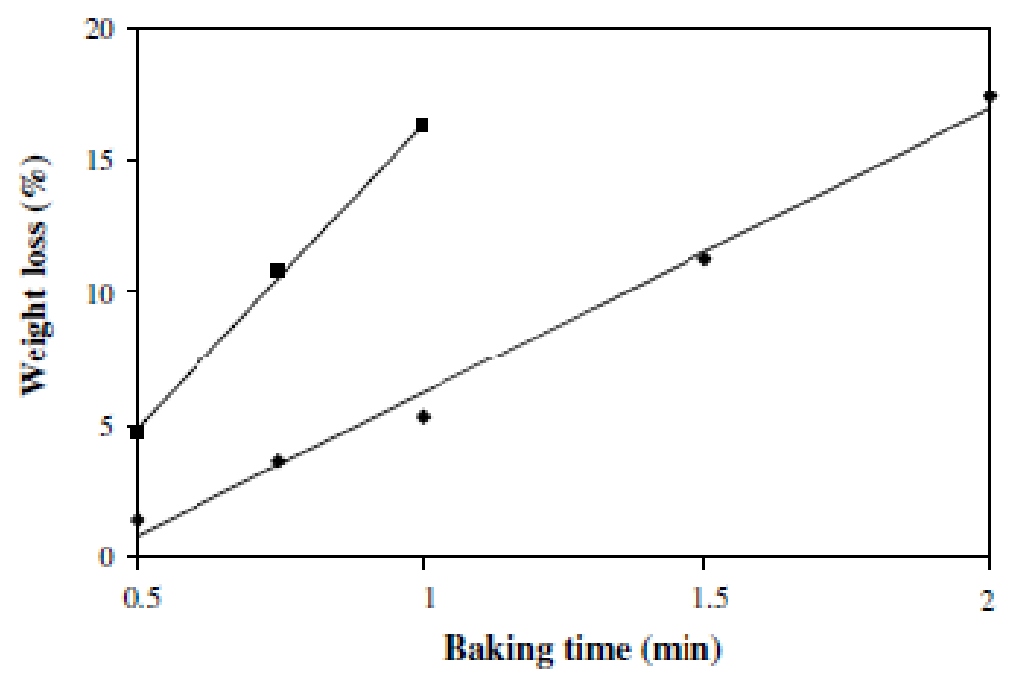

Figure 8. Weight losses of breads during microwave baking at different powers. (४) $50 \%$; (•) $100 \%$. (ref: Keskin et al., 2004)

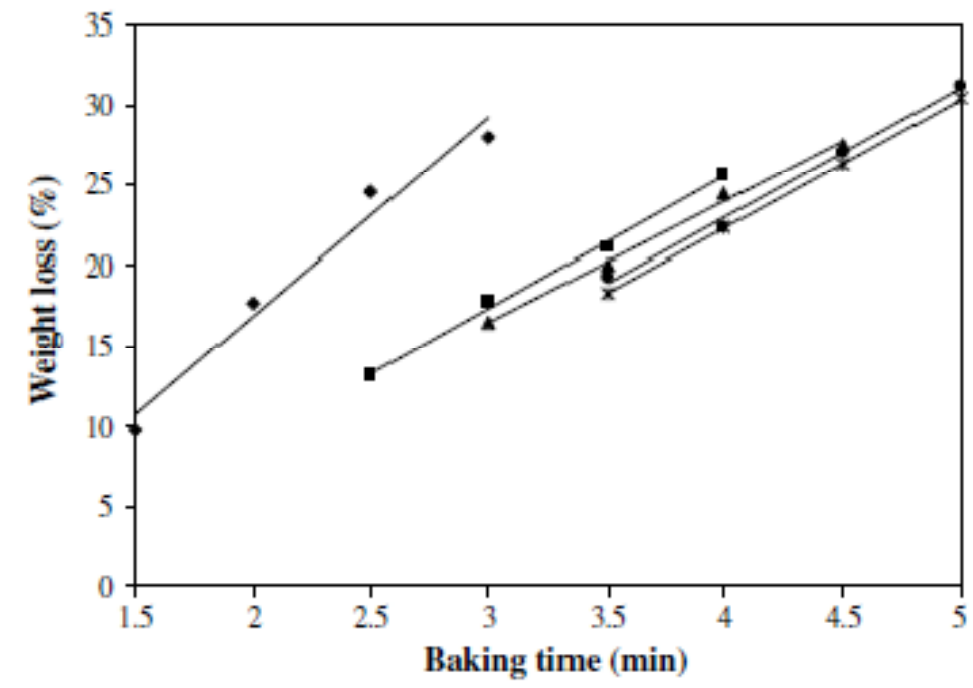

Figure 9. Weight losses of breads during halogen lamp-microwave combination baking at different halogen

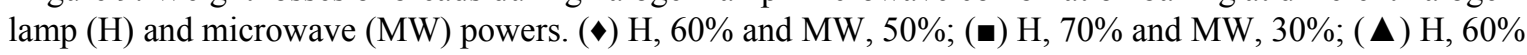
and MW, 30\%; (•) H, 50\% and MW, 30\%; (*) H, 40\% and MW, 30\% (ref: Keskin et al., 2004)

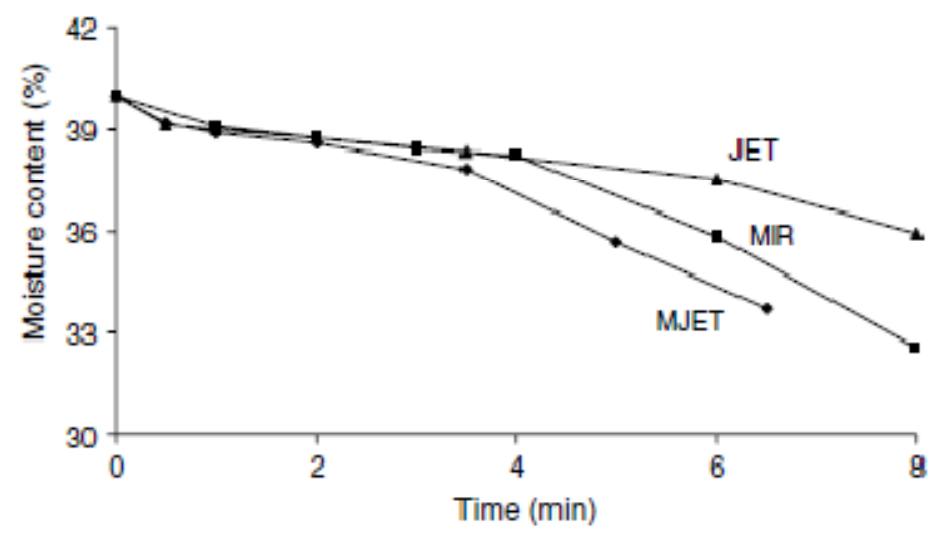

Figure 10. Transient moisture content of breads during baking in different heating modes (ref: Sumnu et al., 2007) 


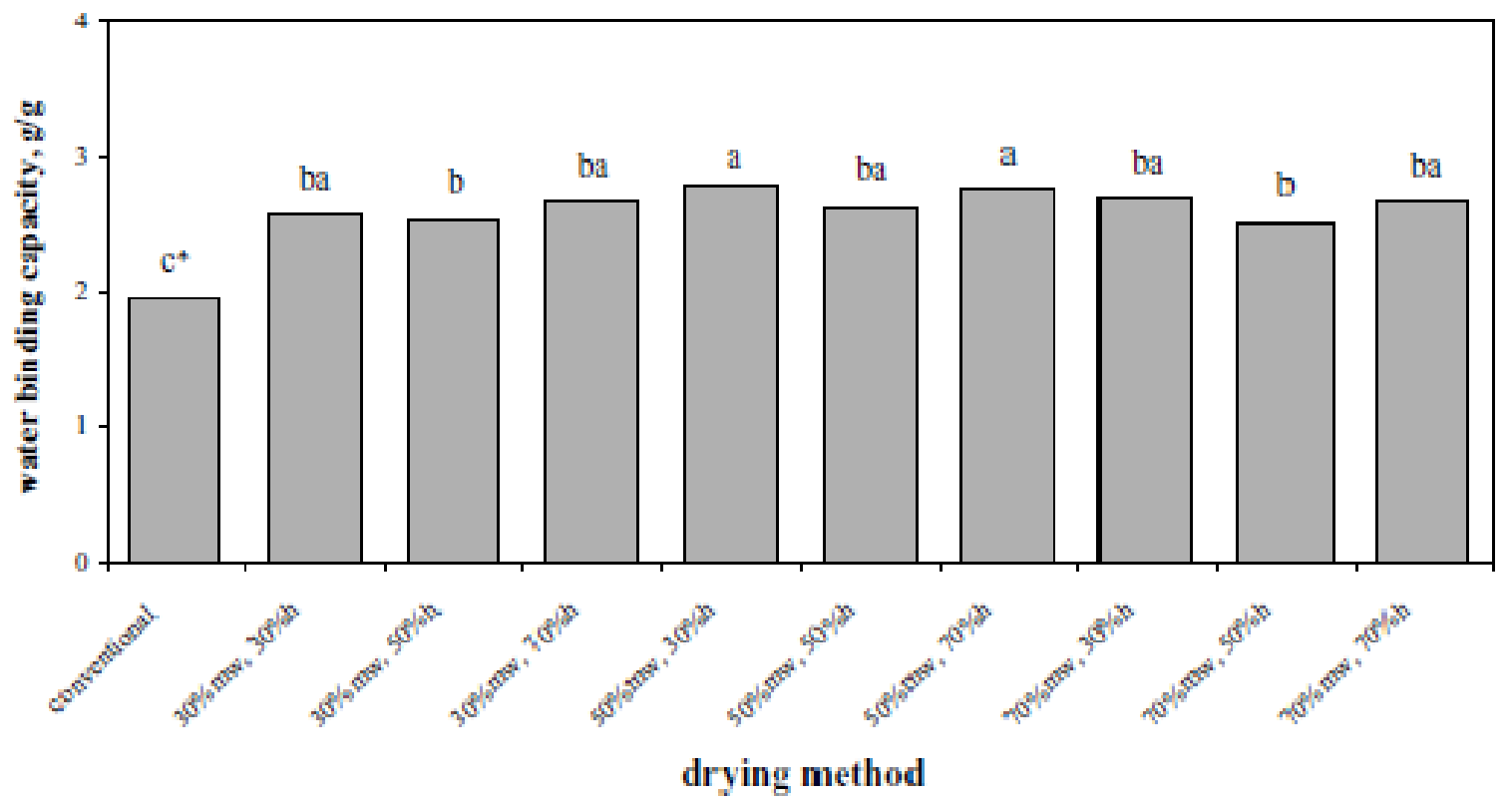

Figure 11. Effect of infrared-assisted microwave drying on water binding capacity of bread crumbs. * Means bars containing different letters are significantly different ( $\mathrm{p} \leq 0.05)$ (ref: Tireki et al., 2006)

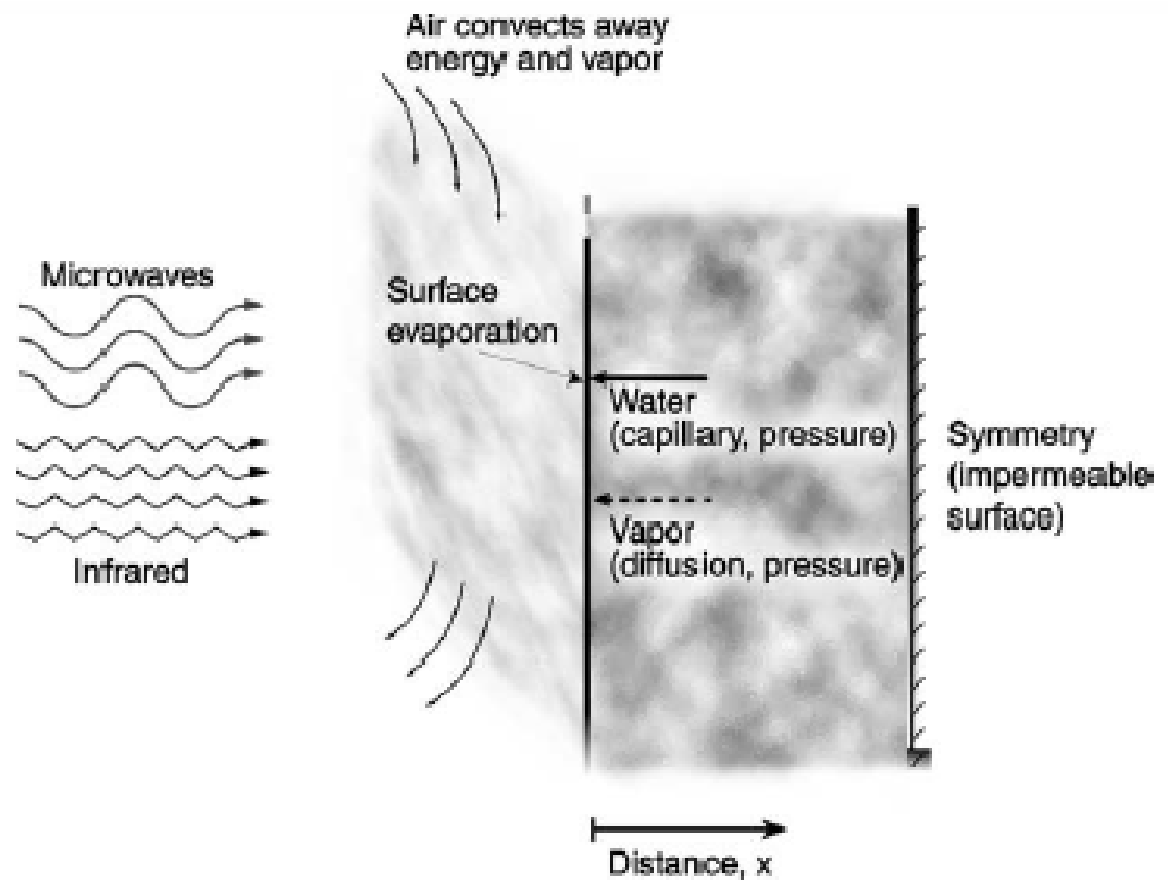

Figure 12. Schematic diagram of the heating process showing transport of liquid water and vapour to the surface from inside, evaporation of liquid water at the surface and convection transport of energy and vapour at the surface (ref: Datta and Ni, 2002) 

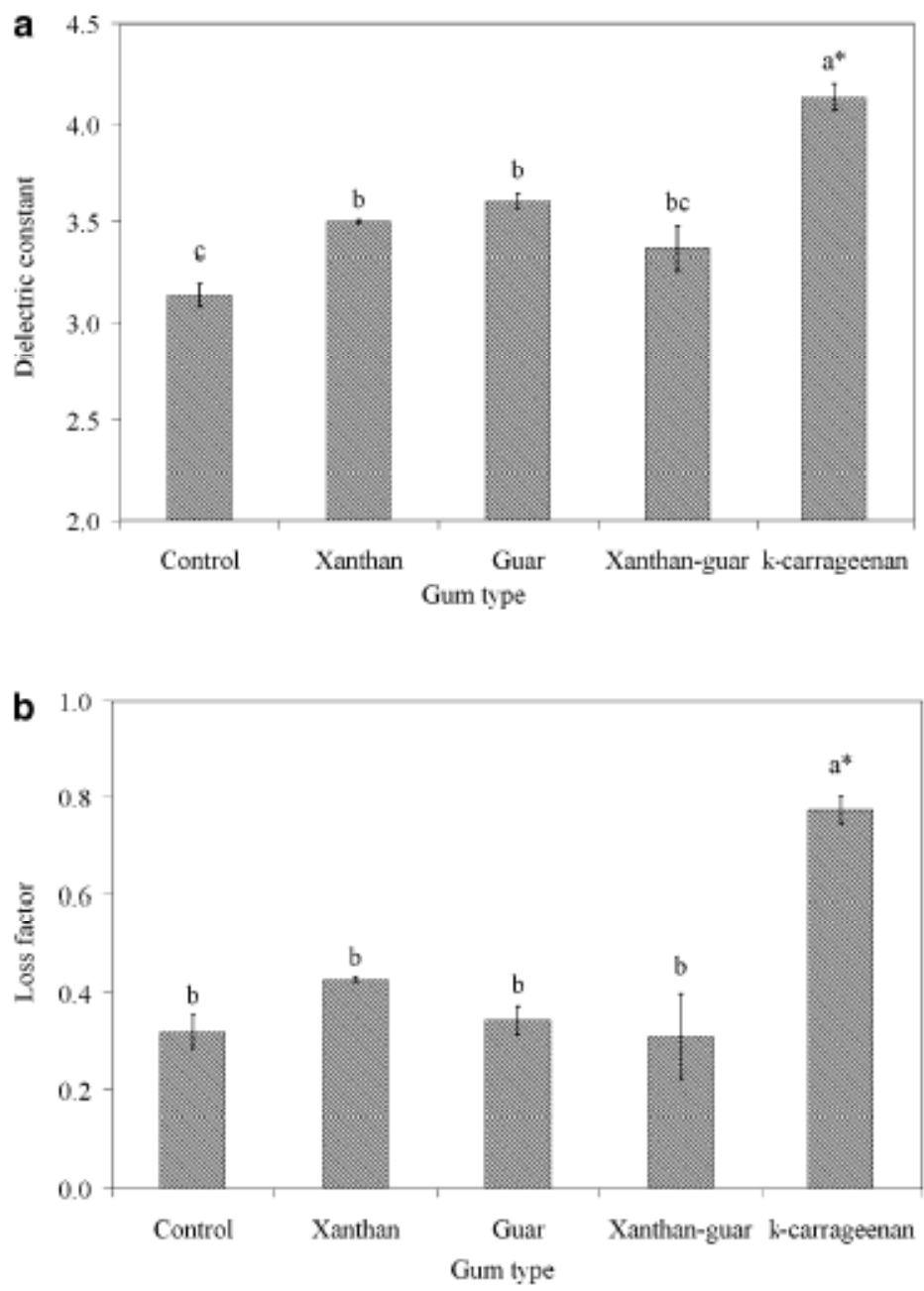

Figure 13. a The effects of different gums on dielectric constant of breads baked in infrared-microwave combination oven (*Bars with different letters ( $a, b, c, d$ ) are significantly different $p \leq 0.05$ ); $b$ The effects of different gums on loss factor of breads baked in infrared-microwave combination oven (*Bars with different letters (a, b, c, d) are significantly different $\mathrm{p} \leq 0.05$ ) (ref: Keskin et al., 2007)

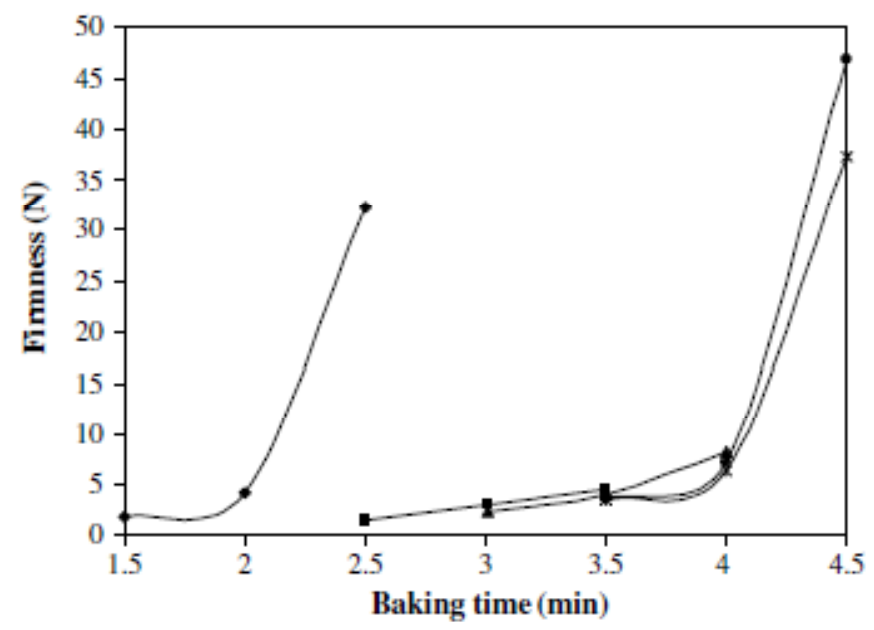

Figure 14. Changes of firmness of breads during halogen lamp-microwave combination baking at different halogen lamp (H) and microwave (MW) powers. ( ) H, 60\% and MW, 50\%; (-) H, 70\% and MW, 30\%; ( $\mathbf{\Delta}) \mathrm{H}$, $60 \%$ and MW, 30\%; (•) H, 50\% and MW, 30\%; (*) H, 40\% and MW, 30\% (ref: Keskin et al., 2004) 


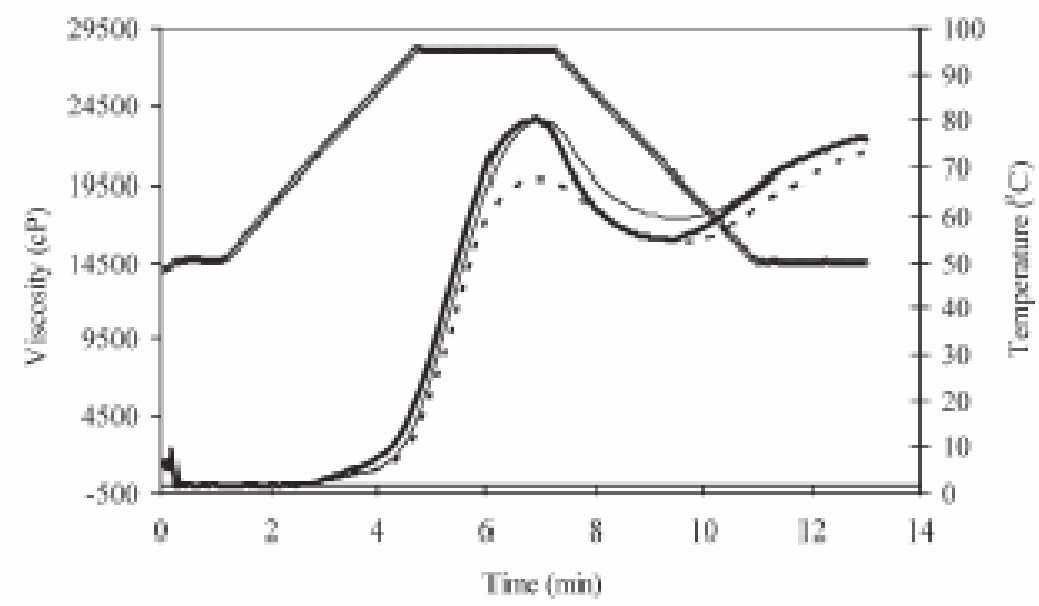

Figure 15. Rapid Visco Analyzer curve for different baking conditions of cookies: conventional (....), microwave (thick continuous line) and halogen lamp-microwave combination (-) baking for $5 \mathrm{~min}$ at $70 \%$ halogen power and $20 \%$ microwave power (ref: Semin Ozge Keskin et al., 2005)

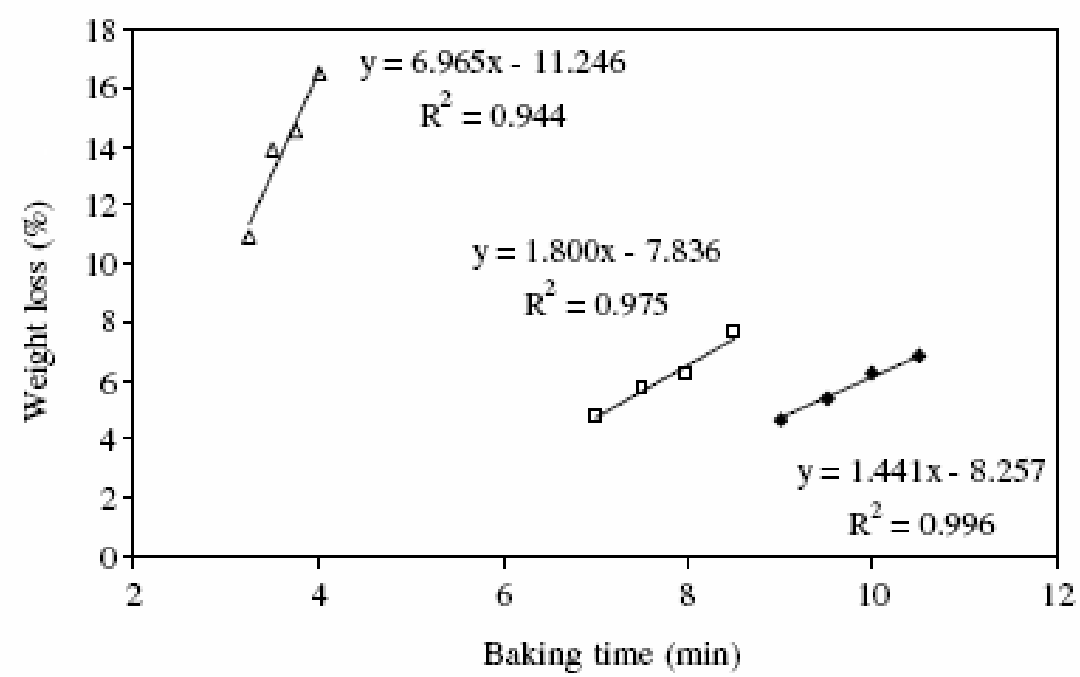

Figure 16. Weight losses of breads during baking by different methods. $(\Delta)$ : Microwave baking at $50 \%$ power, (४): IR baking at $50 \%$ power, ( $\square$ ): IR baking at $70 \%$ power. Markers represent data points and lines represent model equation (ref: Sumnu et al., 2005b) 